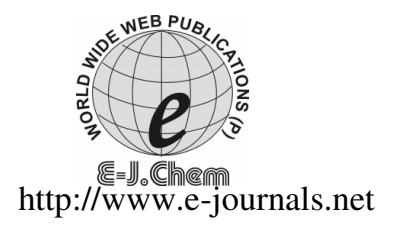

ISSN: 0973-4945; CODEN ECJHAO

E-Journal of Chemistry 2012, 9(1), 181-192

\title{
Synthesis and Characterisation of Novel Cross Linked Biopolyesters from Olive Oil as Eco-friendly Biodegradable Materials
}

\author{
J. SHAKINA* ${ }^{*}$ K. SATHIYA LEKSHMI ${ }^{\S}$ and G. ALLEN GNANA RAJ \\ *Department of Chemistry \\ Sarah Tucker College, Tirunelveli, Tamilnadu, India \\ ${ }^{\S}$ Department of Chemistry, Sri Devi Kumari Women's College \\ Kuzhithurai, Kanyakumari District, Tamilnadu, India \\ Department of Chemistry, Scott Christian College \\ Nagercoil, Kanyakumari District, Tamilnadu, India \\ shakinajudson@gmail.com
}

Received 28 June 2011; Accepted 27 August 2011

\begin{abstract}
Novel cross linked biopolyesters were synthesised from naturally available olive oil, oligomeric polytriglyceride fumarate (o-PTF) was prepared by glycerolysis of the olive oil followed by condensation with maleic anhydride. The (o-PTF) was characterised by spectral (FTIR, UV, NMR) and physicochemical properties (specific gravity, viscosity, saponification value, iodine value). The molecular weight of $o$-PTF was estimated using gel permeation chromatography (GPC). The cross linked biopolyesters were prepared by treating $o$-PTF of olive with $N$-vinyl-2-pyrrolidone and vinyl acetate. The cross linked biopolyesters were evaluated for spectral properties (FT IR), cross linked density, thermal properties, mechanical properties and biodegradation. The potential antifungal and anti bacterial activities of the newly prepared biopolyesters were evaluated. The environment degradation was assessed by soil burial test. The outcome of the studies has revealed that the newly prepared cross linked biopolyesters are potential biodegradable material for various consumer application like package materials and agricultural applications.
\end{abstract}

Keywords: Biopolyesters, Olive oil, $N$-Vinyl-2-pyrrolidone, Vinyl acetate

\section{Introduction}

The replacement of petroleum-based raw materials by renewable resources constitutes a major contemporary challenge in terms of both economical and environmental aspects ${ }^{1}$. 
Natural vegetable oils are considered to be one of the most important classes of renewable sources because of the wide variety of possibilities for chemical transformations, universal availability and low price and they are preferred by the chemical industry as alternative $\mathrm{e}^{2-4}$. The main components of the triglyceride vegetable oils are saturated and unsaturated fatty acids which in its pure form are also available as platform chemicals for polymer synthesis ${ }^{4,5}$. Plant oils are triglycerides (tri-esters of glycerol with long chain fatty acids), with varying composition of fatty acid depending on the plant, the crop, the season and growing conditions ${ }^{6}$ There has been renewed interest recently in developing new polymers from soybean and other plant oils as offer a renewable feed stock against finite and unreliable petroleum sources. Larock et $\mathrm{al}^{7}$ have developed a family of chemically modified plant oils which can be polymerised using free radical initiators, into rigid composites, rubbers and adhesives ${ }^{7}$. Sperling $e t a l^{8}$ have prepared soft rubbers from epoxidised oil cured with acid anhydrides like maleic anhydrides and used the interpenetrating networks to apply on roof tops ${ }^{8}$. Cross linked biodegradable polymers have been prepared from edible oils with unsaturated anhydrides or acids have useful applications as adhesives, fillers and elastomers ${ }^{9}$. These renewable resources have proved to be useful basis for the synthesis of a variety of monomers as well as linear and cross linked polymers of different types (e.g. Polyolefin, polyesters, polyurethane resins and others $)^{10}$. The present study explore the potential utility of the edible oil olive oil for the preparation of the novel cross linked biopolyesters as eco-friendly biodegradable material of various consumers application like packaging material and agricultural application.

\section{Experimental}

Olive oil purchased from Vaighai Chemical Industries Ltd Madurai, India. Formic acid (CDH), hydrogen peroxide (Rankhem), ether (Merck) maleic anhydride (CDH), morpholine (Sigma Aldrich), $N$-vinyl-2-pyrrolidone (Sigma Aldrich), vinyl acetate (Sigma Aldrich) were purchased from respective dealers. All the materials were used without purification.

\section{Synthesis of $o-P T F$ resins}

Glycerolysis of olive oil were carried out using 30\% hydrogen peroxide and formic acid, in ice water bath. The reaction was vigorously stirred over night. The resulting product was poured into a separator funnel and extracted with ether and the ether extracted product was then reacted with maleic anhydride and the mixture was refluxed for $5 \mathrm{~h}$ at $70{ }^{\circ} \mathrm{C}-80{ }^{\circ} \mathrm{C}$ at $160{ }^{\circ} \mathrm{C}$ for 30 minutes under vacuum condition using rota mantle to yield a yellow transparent liquid $o$-PTF resins.

\section{Synthesis of novel cross linked biopolyesters}

The four biopolysters were prepared by free radical polymerisation of $o$-PTF resin of olive oil with cross linking co-monomer $N$-vinyl-2-pyrrolidone and vinyl acetate at room temperature with benzoyl peroxide as free radical indicator and dimethyl aniline as accelerator. To prevent oxygen free radical reaction the resin was purged with nitrogen gas prior to curing and then casted on a clean silicone oil spreaded glass plate, cured for six hours at room temperature. All the cured material showed high toughness, elastomeric and good transparency.

\section{Characterisation of o-PTF resins}

The $o$-PTF resins were subjected to extensive analysis for the determination of specific gravity, iodine value and sap value as per the ISI standard 840 - 1964. The molecular weight was determined by GPC using $\mu$ styragel column, $100 \mathrm{~A}^{0}$ and $500 \mathrm{~A}^{0}$, UV detector and $280 \mathrm{~nm}$ filter. The $o$-PTF were analysed by UV, IR, NMR spectral analysis. 


\section{Characterisation of biopolyesters}

The AT - IR spectral analysis of the four biopolyesters was done by perkin 597 infrared spectrophotometer. The Tensile strength of the biopolyesters were determined using Dumbbell shaped cut from the specimen using ISO 527 - 2:1993 (E) specimen type SA die. The values represented are an average mean of about 6-10 samples. The thermal analysis of the biopolyesters were determined by simultaneous DTA - TGA and DSC using SDT - 2960 TA instruments INC derived from ASTME $1131-03$.

\section{Test for biodegradability}

\section{Soil burial test}

The replicate pieces of the sample $(5 \times 3 \mathrm{~cm})$ were buried in the garden soil at the depth of $30 \mathrm{~cm}$ from the ground surface for 3 months, inoculated with the sewage sludge having ability to adhere and degrade the polymer film. The test specimen was periodically removed from the soil and the specimen was then gently washed to remove attached soil and dust after being dried in vacuum oven. The extent of degradation was examined by weight loss and surface observation.

\section{Microbial studies}

Bacterial adhesion and antimicrobial activity were evaluated by agar diffusion method the microbial strains used are Escherichia coli (gram positive bacteria) and Candida albicans (fungi).

\section{Results and Discussion}

Olive oil is a mixed glyceride of unsaturated components (linoleic acid, oleic acid) and saturated compound (palmitic and stearic acid), since the concentration of unsaturated compounds are higher the mixed unsaturated triglyceride molecule offers a number of reactive sites, $\mathrm{C}=\mathrm{C}$ bonds, the carbon alpha to the ester group for functionalisation ${ }^{11,12}$. Under the present experimental conditions hydroxylation takes place at the double bonds of the triglyceride units. The reaction of hydroxylated olive oil with maleic anhydride catalysed by morpholine lead to the formation of oligomeric-poly triglyceride fumarate (o-PTF) resin, the analysis of these resins reveals the formation of $o$-PTF resins. The analytical data are given in Table 1, finally the cross linking of $o$-PTF resins involves the reaction of unsaturated sites in the polymer chain with a co-monomer which may be of vinyl type such as vinyl acetate and $\mathrm{N}$-vinyl-2-pyrrolidone to form biopolyesters of olive oil.

Table 1. Physical properties

\begin{tabular}{lccc}
\hline \multicolumn{1}{c}{ Parameter } & olive oil & Gly-olive & O-PTF olive \\
\hline Specific gravity gm/cc at $30{ }^{\circ} \mathrm{C}$ & 0.924 & 0.889 & 0.722 \\
Sapvalue mg KOH / gm & 190.4 & 164.9 & 86.6 \\
Iodine Index & 120.32 & 6.72 & 53.72 \\
Visocity & 0.925 & 1.264 & 1.22 \\
Mol Wt / Sap test & 886 & 1024 & 1939.95 \\
Mol wt / Cal & 882 & 1018 & 1938 \\
Mol wt (GPC) & 892 & 1032 & 1946 \\
Hydroxyl Number & - & 9.72 & 0.723 \\
\hline
\end{tabular}

Iodine value represents the degree of unsatuaration (= bonds) in the triglyceride oil. The high iodine value of olive oil indicates the higher concentration of unsaturated compound in 
the parent oil. In the hydroxylated resin iodine value is decreased drastically revealing that the double bond is replaced by hydroxyl group. The hydroxyl value determined the number of hydroxyl groups. The iodine values is increased significantly in the $o$-PTF resins due to the unsaturated fumarated side chain in the $o$-PTF resins

Saponification is applied to the hydrolysis of fatty acid ester under alkaline condition. Saponification number is used for the determination of the size, average molecular weight of the fatty acid and to estimate the non fatty impurity if present. Therefore the molecular weight of the compounds were determined from the relation molecular $=$ weight $=168,000$ / Sap value. The molecular weight determined by this method match the calculated value. The saponification value reveals that the molecular weight of $o$-PTF resin has increased compared to the oil

\section{Spectral analysis of $o-P T F$ resin}

The UV spectrum of olive oil shows an absorption peak at about $230 \mathrm{~nm}$ (ester). The UV spectrum show a shift of peak from $230 \mathrm{~nm}$ for oil to 259 for hydoxylated resin due to the hyper chromic effect which is attributed to the substitution of the unsaturated group. In the $o$-PTF resins the peak is again shifted back to $235 \mathrm{~nm}$ due to hypo chromic effect which is attributed to the distortion of geometry by the introduction of fumarate group ${ }^{13}$.

\section{IR spectral analysis}

The IR spectra of olive oil, HTO resins, $(o-\mathrm{PTF})$ resins are recorded between $500 \mathrm{~cm}^{-1}$ to $4500 \mathrm{~cm}^{-1}$ (Figure 1-3). In hydroxylated triglyceride resins, the IR spectra showed a strong absorption band at $3465.84 \mathrm{~cm}^{-1}$, due to the present of free - OH group in the molecule. The corresponding peak is completely reduced in the $o-\mathrm{PTF}$ resins indicates the - entire $\mathrm{OH}$ group get substituted. A strong absorbance band in $2925.81 \mathrm{~cm}^{-1}$ is due to the presence of $\mathrm{C}=0$ of the glycerol ester moiety. A strong band in $2854.45 \mathrm{~cm}^{-1}$ is due to the symmetrical $-\mathrm{C}-\mathrm{H}$ bond in $-\mathrm{CH}_{2}-$ group of the side chain.

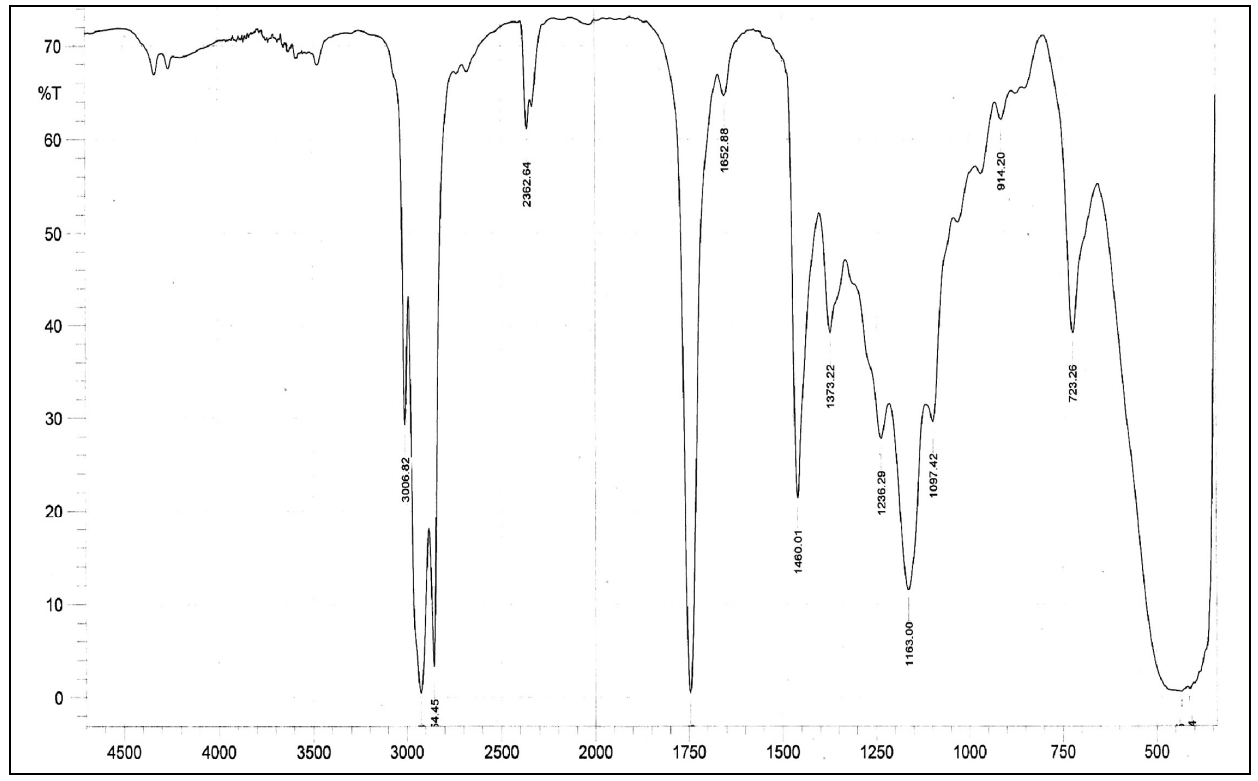

Figure 1. IR spectrum of olive oil 


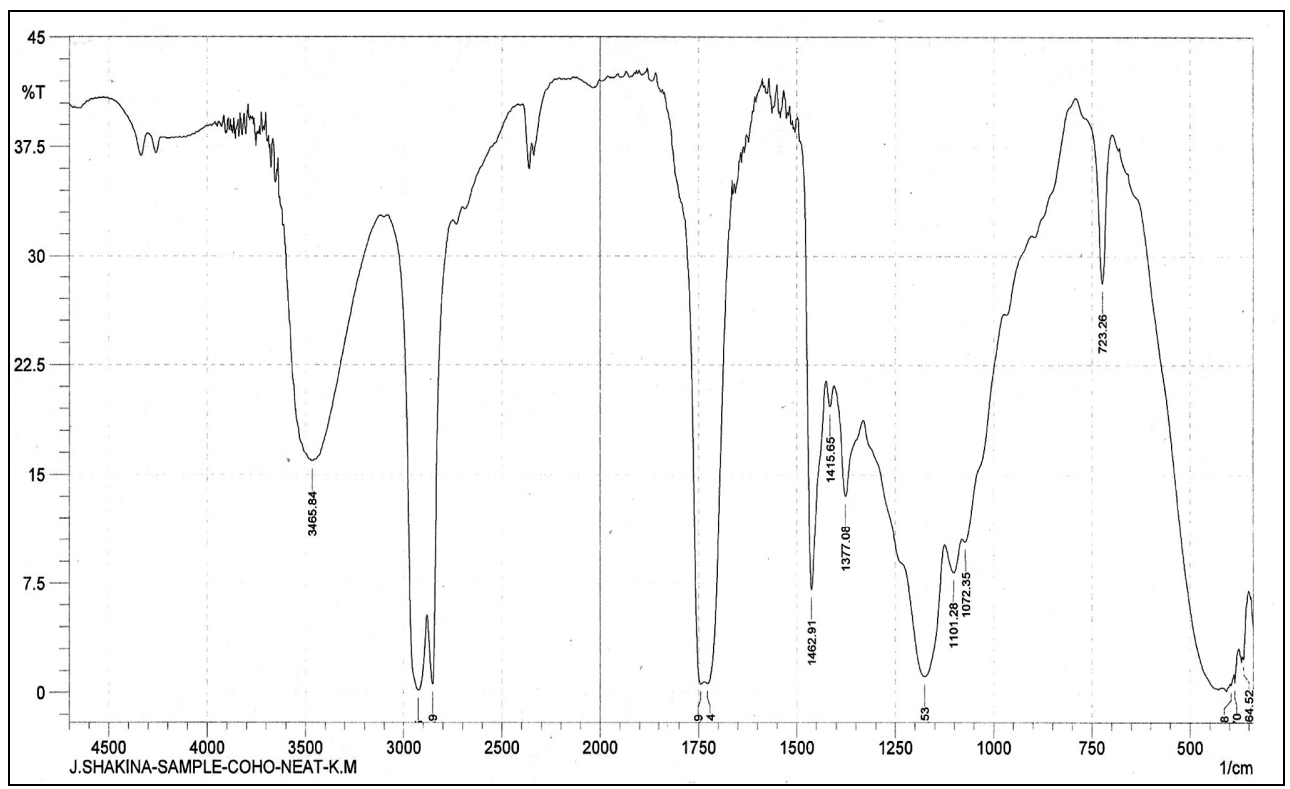

Figure 2. IR spectrum of hydroxylated olive oil

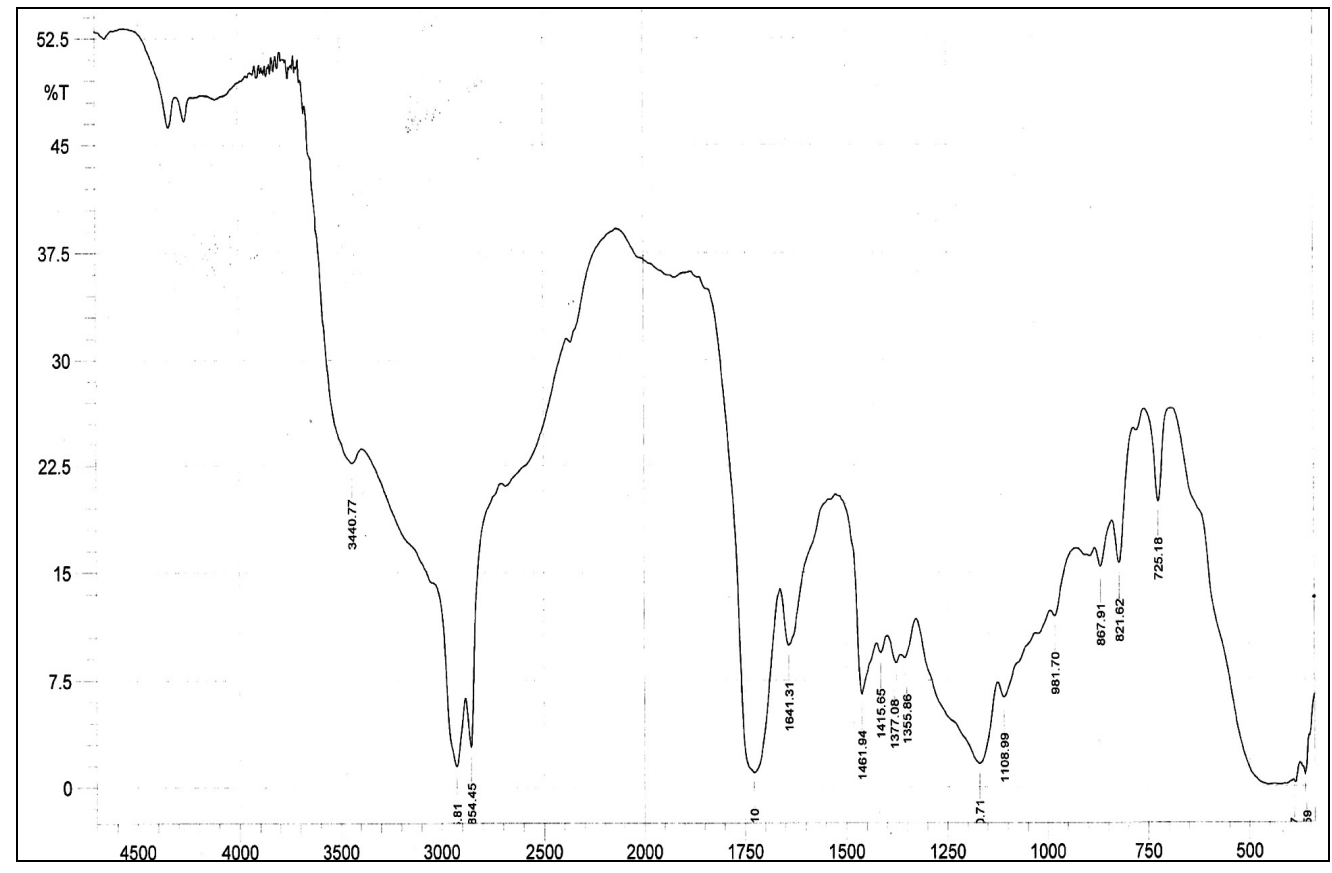

Figure 3. IR spectrum of $o$-PTF resin olive oil

The IR spectrum of $o$-PTF - olive oil -co- vinyl acetate polyesters are shown in the Figure 4. The responses at $2925 \mathrm{~cm}^{-1}$ is due to the aliphatic C-H group in the chain, the peak at $1730 \mathrm{~cm}^{-1}\left(\mathrm{C}=\mathrm{O}\right.$ stretch in esters) and peak at $1454 \mathrm{~cm}^{-1}$ is due to $\mathrm{CH}_{2}$ linkages and the peak at $1372 \mathrm{~cm}^{-1}$ is due to $\mathrm{CH}_{3}$ group and $3500 \mathrm{~cm}^{-1}$ is due to $\mathrm{OH}$ group. 


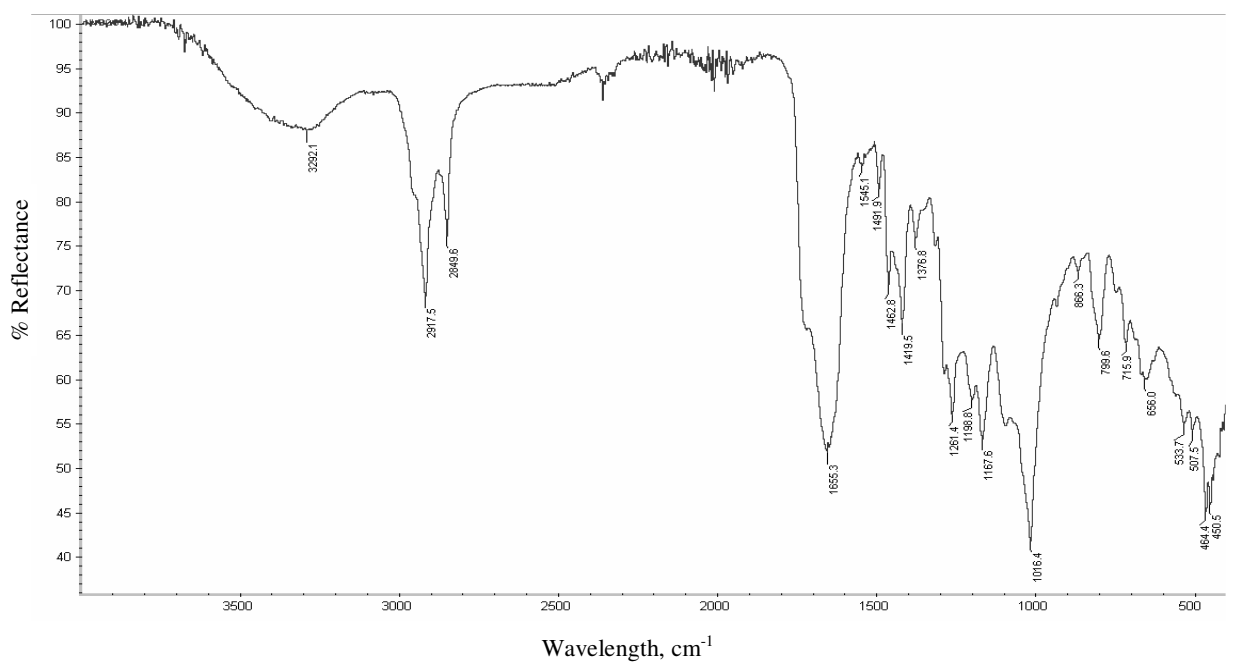

Figure 4. IR spectrum of $o$-PTF - olive oil -co- vinyl acetate polyester

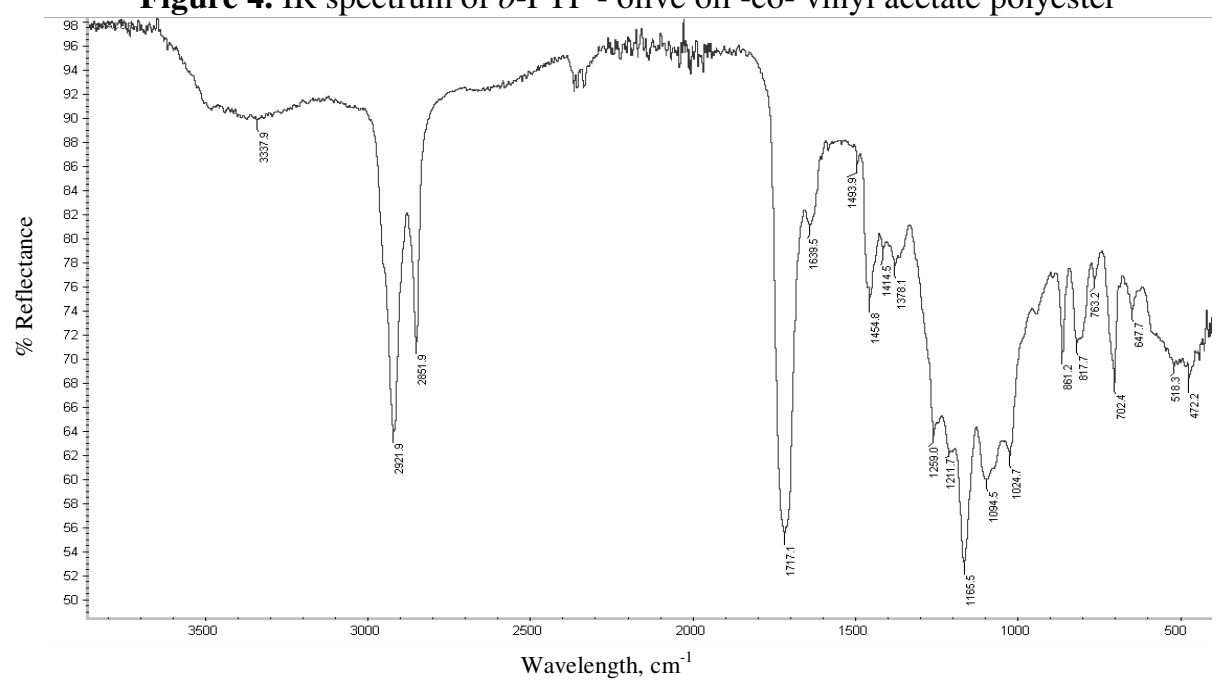

Figure 5. IR spectrum of $o$-PTF - olive oil -co $N$-vinyl pyrrolidone polyester

The IR spectrum of $o$-PTF-olive oil-co - $N$-vinyl-2-pyrrolidone biopolyesters are shown in Figure 5. The spectrum shows responses at $2924 \mathrm{~cm}^{-1}$ due to the aliphatic $-\mathrm{CH}$ groups in the chain, the peak at $1723 \mathrm{~cm}^{-1} \mathrm{C}=\mathrm{O}$ stretch in esters and peak at $1645 \mathrm{~cm}^{-1}$ is due to $\mathrm{CH}$ bending of trans $\mathrm{CH}=\mathrm{CH}$ and the peak at 1021 is due to $\mathrm{C}=\mathrm{C}$ stretching.

The possible peaks in ${ }^{1} \mathrm{H}$ NMR for quantitating unsaturated fatty acids are those of olefinic protons (5.3-5.4 ppm), protons attached to the bis-allyllic carbons (2.7-2.8 ppm), protons attached to alliylic carbon (2.0-2.1 ppm), methylene $-\mathrm{CH}_{2^{-}}(1.2-1.4 \mathrm{ppm})$ and the terminal methyl protons (0.8-0.9 ppm) shown in the (Figure 6). The corresponding olefinic protons peak in the glycerolysis product has almost disappeared (Figure 7), showing the double bonds in oil is replaced by the hydroxyl group. This peak is shifted to 3.1-3.2 ppm in the $o$-PTF resins due to the deshielding effect of hydroxyl and carboxylate ester linkages (Figure 8). 
Table 2. Chemical shift and assignment of the signal in the ${ }^{1} \mathrm{H}$ NMR spectrum of olive oil in pyridine- $\mathrm{d}_{5} /$ chloroform $-\mathrm{d}$ solvent

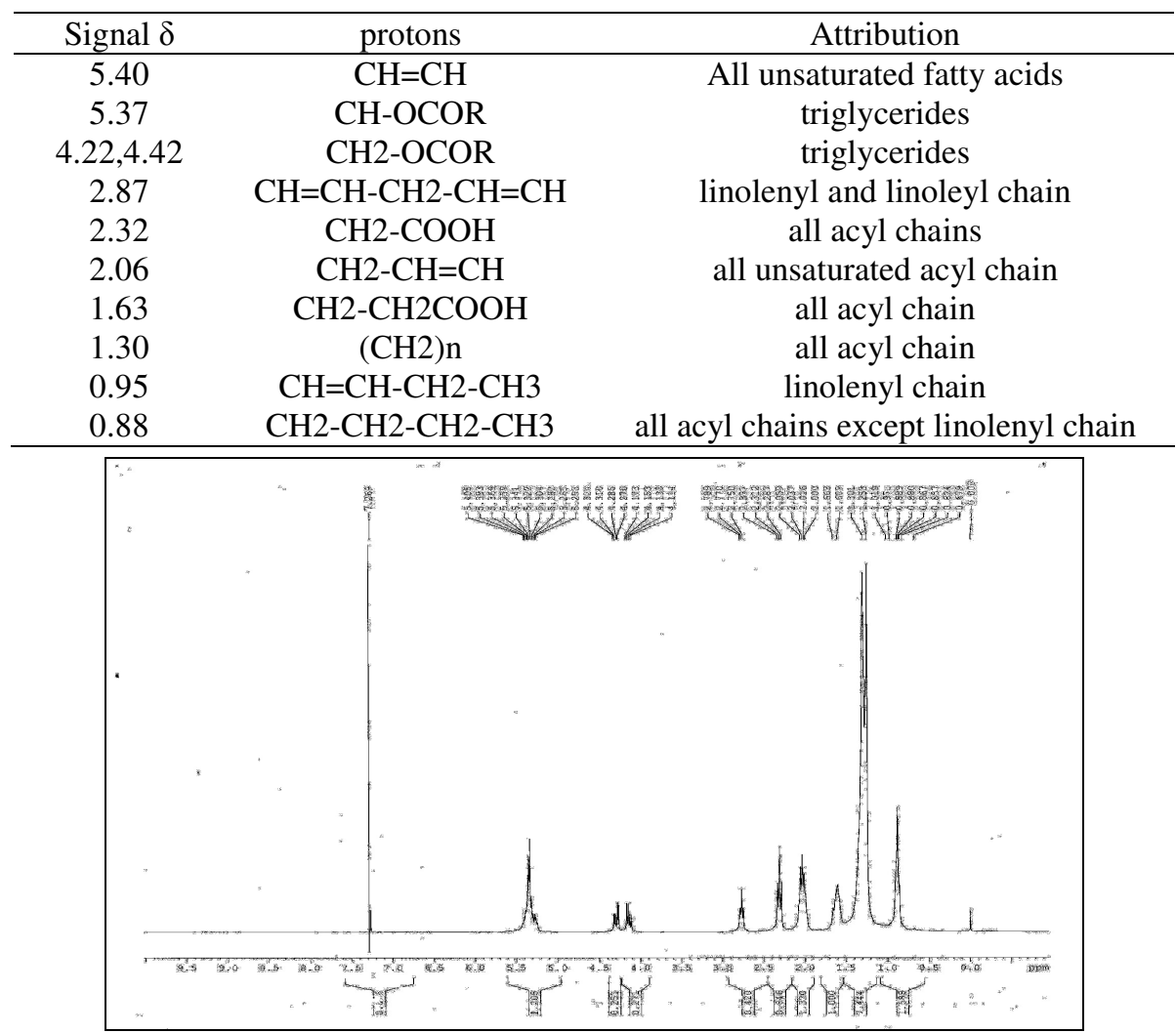

Figure 6. NMR Spectrum of olive oil

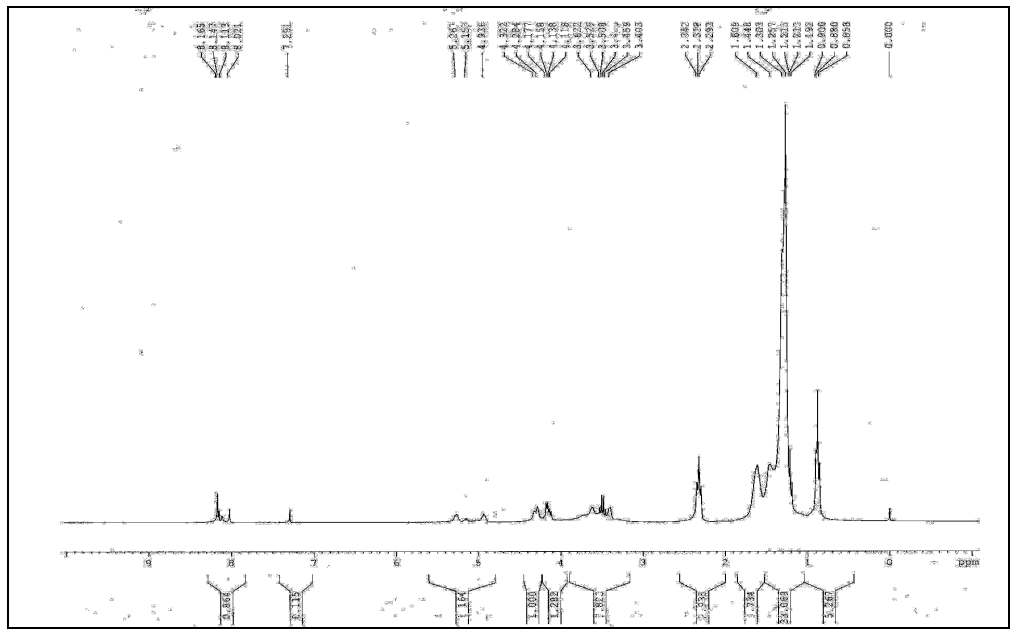

Figure 7. NMR spectrum of hydroxylated olive oil 


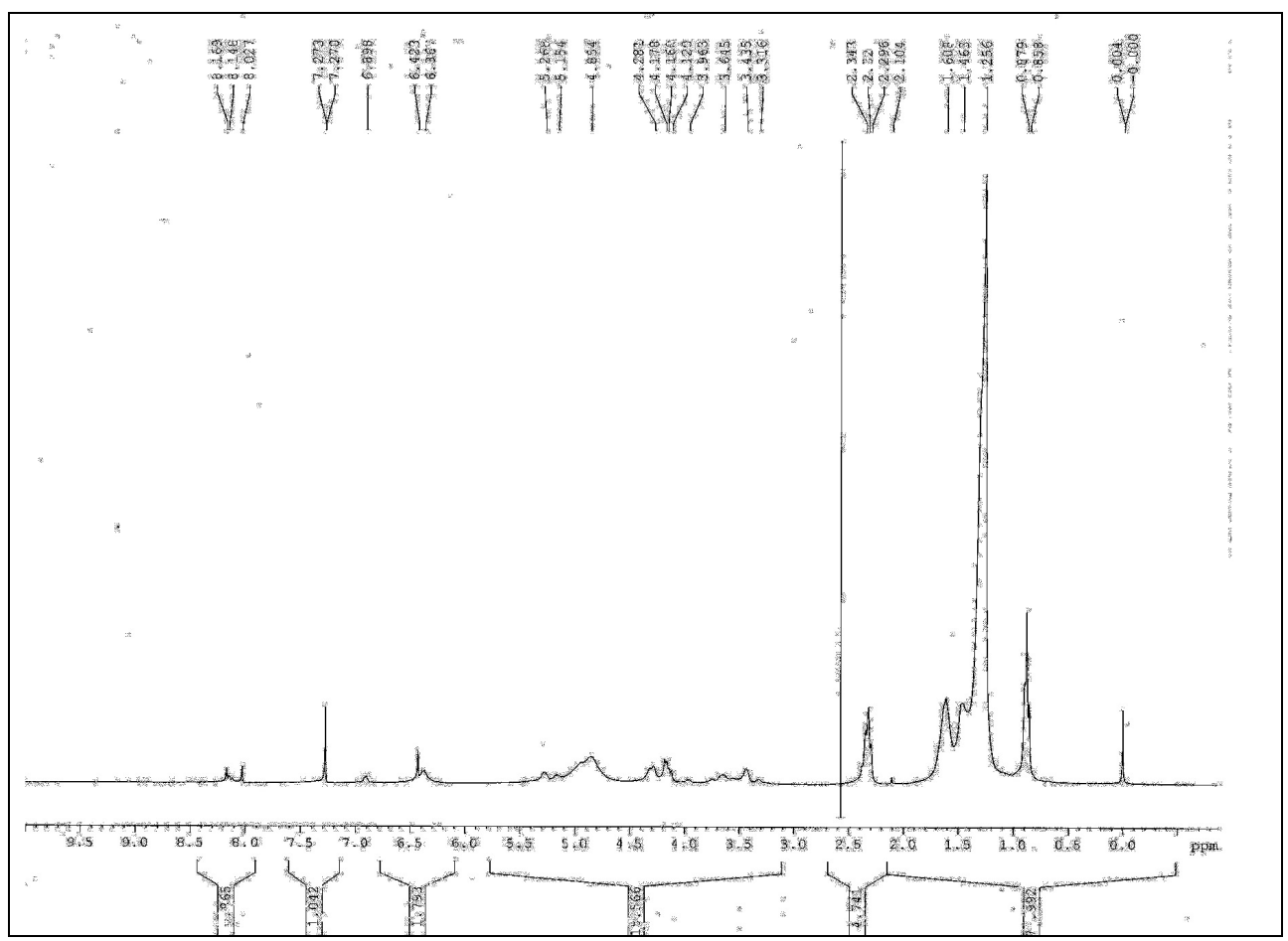

Figure 8. NMR spectrum of $o$-PTF olive oil

\section{Thermal properties}

The thermal properties of biopolyesters of $o$-PTF-Co- vinyl acetate (OLIVA) and $o$-PTFCo- $N$-vinyl-2-pyrrolidone (OLINVP) studied were influenced mainly by molecular weight between crosslink and the degradation to which segment form stiff sequence and elastically active branch points ${ }^{14,15}$. The segments constitute stiff sequences are vinyl monomers substituted fumarate groups. The DTA curve show multi - stage endothermic peaks characterising thermal decomposition the DTA curves (Figures $9 \& 10$ ) are the biopolyesters indicates more than 3 endotherms above $200{ }^{\circ} \mathrm{C}$ due to chain scission and degradation. This is well exhibited by the weight loss starting from the temperature in the TGA curves. The first stage of degradation and weight loss is due to the initial degradation of vinyl monomer present in the fumarate ester linkage chain at low temperature which is due to the flexibility of the vinyl group even in the cross linked state of biopolyesters. The DSC studies revealed the glass transaction temperature the $\mathrm{T}_{\mathrm{g}}$ values clearly indicates the polymer are semi crystalline in nature (Table 4).

Table 3. Thermal properties

\begin{tabular}{cccccc}
\hline \multirow{2}{*}{ Biopolyesters } & \multicolumn{5}{c}{ Temperature $^{0} \mathrm{C}$ at the each stage of degradation (weight loss \%) } \\
\cline { 2 - 6 } & $\mathrm{T}_{\text {start }}$ & $1^{\text {st }}$ & $2^{\text {nd }}$ & $3^{\text {rd }}$ & $4^{\text {th }}$ \\
\hline \multirow{2}{*}{ OLIVA } & \multirow{2}{*}{142.86} & 278.59 & 366.22 & 451.20 & 722.20 \\
\multirow{2}{*}{ OLINVP } & \multirow{2}{*}{137} & $(8.62)$ & $(38.63)$ & $(83.63)$ & $(97,34)$ \\
& & 229.84 & 342.09 & 403.77 & 448.9 \\
& & $(11.85)$ & $(20.86)$ & $(81.72)$ & $(89.04)$ \\
\hline
\end{tabular}




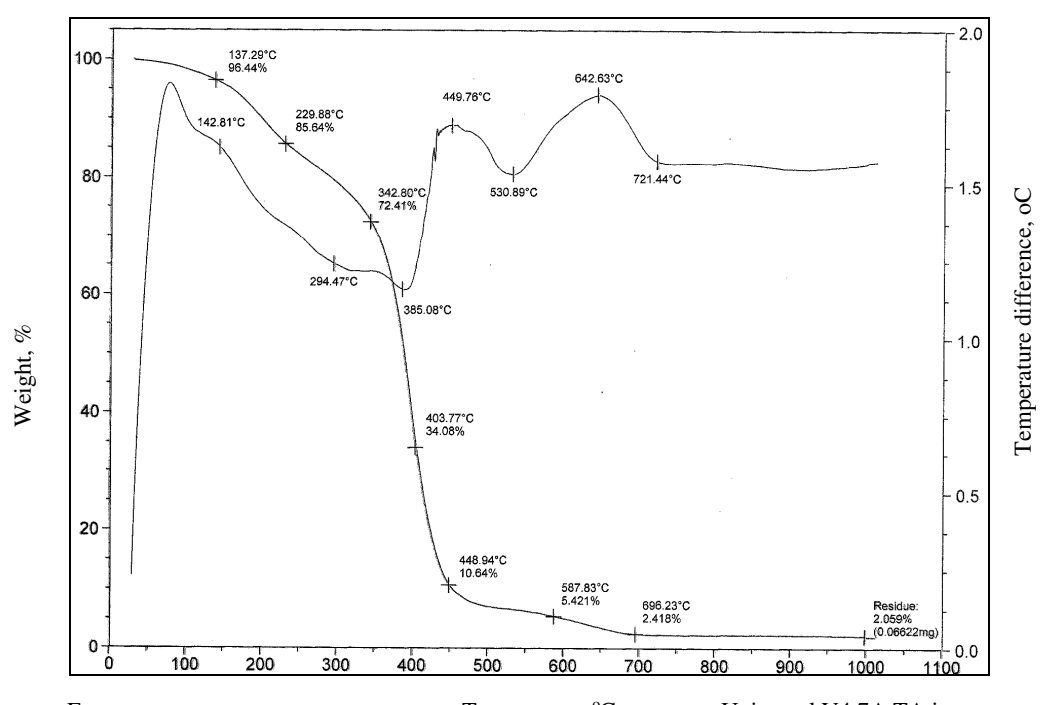

Exp up Temperature ${ }^{\circ} \mathrm{C} \quad$ Universal V4.7A.TA instruments

Figure 9. The TGA-DTA curve for OLIVA

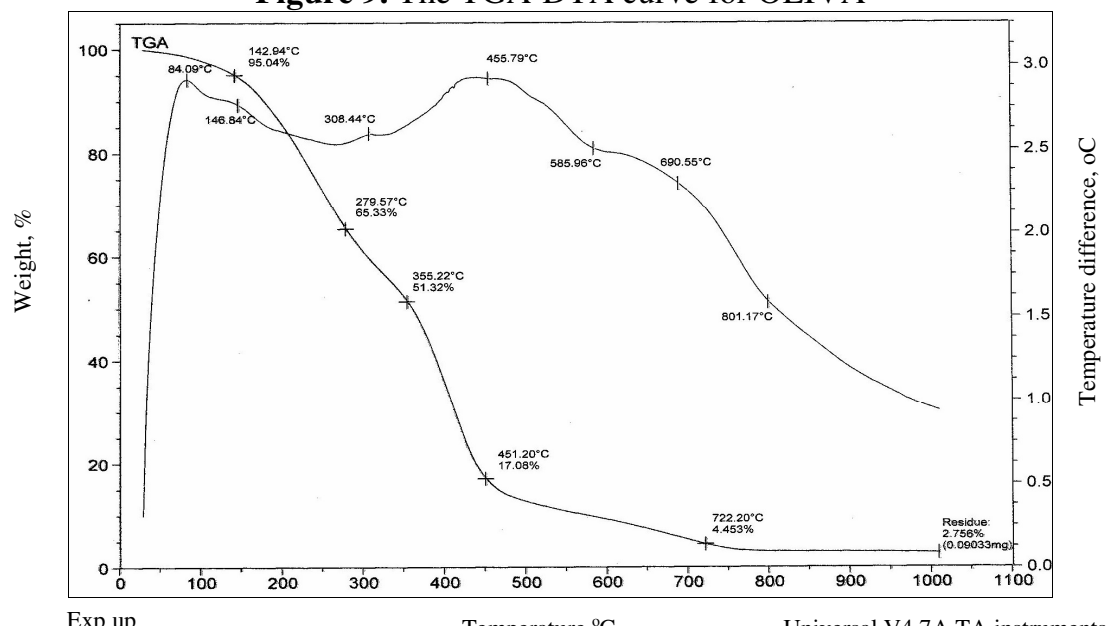

Figure 10. The TGA-DTA curve for OLINVP

Table 4. DSC characterisation

\begin{tabular}{ccc}
\hline Biopolyesters & $\mathrm{T}_{\mathrm{g}}{ }^{\circ} \mathrm{C}$ & $\Delta \mathrm{Hm},{ }^{\circ} \mathrm{C}$ \\
\hline OLIVA & 63.36 & $173.79,477.96$ \\
OLINVP & 77.68 & $184.91,328.0,471.22$ \\
\hline
\end{tabular}

\section{Mechanical properties}

The data of mechanical properties of all the cure samples are shown in the Table 3 . The higher tensile strength and modulus are observed in vinyl acetate biopolyesters than $\mathrm{N}$-vinyl-2pyrrolidone biopolyesters. The modification with MA increases the chemical functionality of the biopolyester resins results in a increasing cross linked density thus from these results 
the modulus and strength of triglyceride based biopolyesters can be increased by simply increasing the chemical functionalities of the triglycerides ${ }^{16}$. The high strength and high modulus reflect the strong and hard character of these poly esters (Table 5)

Table 5. Mechanical properties

\begin{tabular}{cccc}
\hline Sample & Tensile strength MPa & Strain at Break \% & Modulus \\
\hline OLIVA & $11.143 \pm 0.07$ & $51.6 \pm 6.5$ & $9.8 \pm 1.7$ \\
OLINVP & $21.99 \pm 0.2$ & $78.5 \pm 4.8$ & $7.7 \pm 0.2$ \\
\hline
\end{tabular}

\section{Biodegradation test}

\section{Soil burial test}

The biopolyester films $6 \times 3 \mathrm{~cm}$ were buried in soil for 6 months for isolation of degrading microbe. It was found that a remarkable degradation was indicated in the sample (Figure 11). The percentage of weight loss was low between 30 and 40 days After 40 days the degradation was rapid from this results triglycerides cross linked with hydrolysable bonds such as esters remain biodegradable ${ }^{17}$.

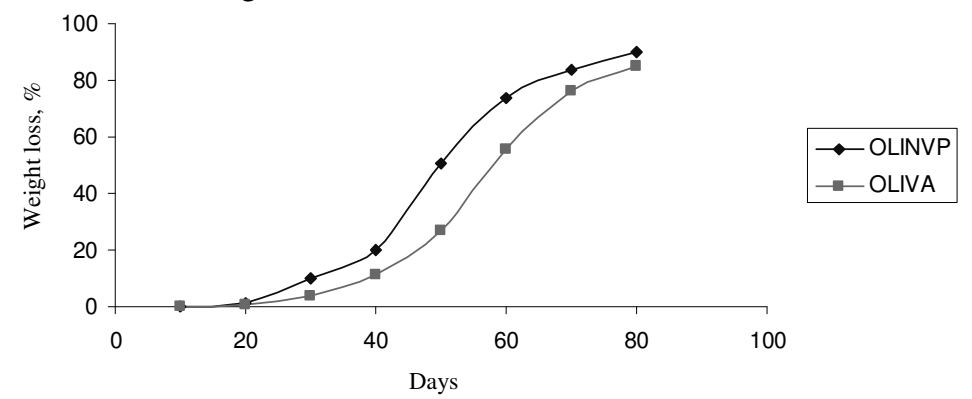

Figure 11. Analysis of soil burial test

\section{Aerobic test}

The aerobic biodegradability of polymeric resins in a aqueous medium was evaluated by determining the oxygen requirement in a closed respirometry (Germany standard ISO 9408 .1999) the degradation rate $=$ BOD / COD x 100 was calculated. From the results (Table 6) the degradation rate is faster after 45 days i.e. longer the sample is subjected to the aerobic test, the faster the degradation rates. When compared to soil burial test aerobic degradation is much faster.

Table 6. Aerobic test

\begin{tabular}{ccccc}
\hline Sample Code & Average BOD & COD & Biodegradation, \% & Degradation days \\
\hline OLINVP & 619 & 1.113 & 88 & 60 \\
OLIVA & 520 & 0.821 & 91 & 60 \\
\hline
\end{tabular}

\section{Bacterial adhesion test}

The biopolyesters were incubated on mineral salt agar medium inoculated with isolated bacterial and fungi strain. Degradation of several of these polymers proceeds through adsorption of the micro organism to the polymer surface followed by hydrolytic cleavage. S.aureus species degrades polyesters. 
Table 7. Viable count / sample for biopolyester

\begin{tabular}{ccc}
\hline \multirow{2}{*}{ Sample code } & \multicolumn{2}{c}{ Number of bacteria adhered / sample } \\
\cline { 2 - 3 } & E.Coli $\times 10^{-6} c f u$ & S.aureus $\times 10^{-6} c f u$ \\
\hline OLINVP & 0.51 & 2.32 \\
OLIVA & 2.63 & 2.52 \\
\hline
\end{tabular}

\section{Antimicrobial activity}

The newly prepared biopolyesters have been studied against bacterial and fungi strains (Figure 12). The $\mathrm{N}$-vinyl-2-pyrrolidone biopolyesters showed potential anti bacterial and anticandidal activity against micro organisms (Table 8).

Table 8. Antimicrobial studies with zone of inhibition (mm)

\begin{tabular}{ccc}
\hline Sample code & E.coli & Candida albicans \\
\hline OLINVP & 17 & 13 \\
OLIVA & 6 & 4 \\
Gentamycin-10 mg & 24 & 19 \\
\hline & & \\
& & \\
&
\end{tabular}

Figure 12. Antimicrobial studies of OLINVP with zone of inhibition

\section{Conclusion}

Natural oils are expected to be inexpensive renewable resources development of new polymeric materials from vegetables oil is highly desirable. The purpose of this work is to prepare high molecular weight polymers and it would be alternative petroleum based polymeric materials such as plastic and rubber materials. The present method of in situ glycerolysis of the oil followed by condensation with maleic anhydride and the Four cross linked biopolyesters were prepared by treating $o$-PTF of olive oil with $N$-vinyl-2-pyrrolidone and vinyl acetate. The outcome of those studies has revealed that the newly prepared cross linked biopolyesters are potential biodegradable material for various consumer application like package materials and agricultural applications.

\section{References}

1. Williams C K and Hillmeyer M A, Polym Rev. 2008, 48, 1-10.

2. Bierman U, Friedt W Lang S and Luhs W, Machmuller G, Metzger J O, Klaas M R, Schafer H J and Schneider M P, Angew Chem Int Ed., 2000, 39, 2206- 2224.

3. Clark J H, Budarin V, Deswarte F E I, Hardy J J E, Kerton F M, Hunt A J, Luque R, Macquarrie D J, Milkowssi K, Rodriquez A, Samuel O, Tavener S J, White R J and Wilson A J, Green Chem., 2006, 8, 853-860.

4. Guner F S, Yagci Y and Erciyes A T, Prog Polym Sci., 2006, 31,633-670.

5. Sharma V and Kundu P P, Prog Polym Sci., 2006, 31, 983-1008.

6. Meier M A R, Metzger J O and Schubert U S, Chem Soc Rev., 2007, 36, 1788-1802. 
7. Lu Y and Larock R C, Chem Sus Chem., 2009, 2, 136-147.

8. Sperling L H, Polymeric Multicomponent Materials, An Introduction, Wiley, Newyork, 1997.

9. Juan Carlos Ronda, Gerard Lligadas, Marina Galià, Virgínia Cádiz, Eur J Lipid Sci Technol., 2011, 113(1), 46-58

10. Park S J, Jin F L and Lee J R, Macromol Rapid Comm., 2004, 25(6), 724-727.

11. Eren T and Kuisefoglu S.H and wool R, J Appl Polym Sci., 2003, 90(1), 197-202.

12. Eren T, Kuisefoglu S H and Wool R, J Appl Polym Sci, 2005, 97, 2264-2272.

13. Sharma V and Kundu P P, Prog Polym Sci., 2008 33, 1199-1215.

14. Eren T and Kuisefoglu S H, J Appl Polym Sci., 2004, 91(4), 2700-2710.

15. Sionakidis J, Sperling L H and Thomas D A, J Appl Polym Sci., 1979, 24, 1179.

16. Li F Hanson M V and Larock R C, Polymer, 2001, 42, 1567-1579.

17. Güner F S Yagci Y and Erciyes A T, Prog Polym Sci. 2006, 31, 633-670. 


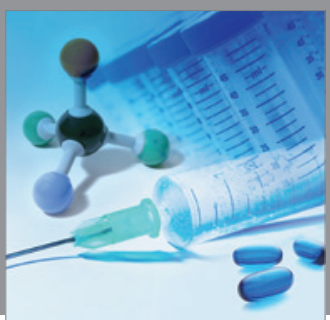

International Journal of

Medicinal Chemistry

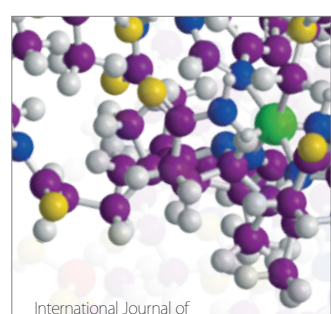

Carbohydrate Chemistry

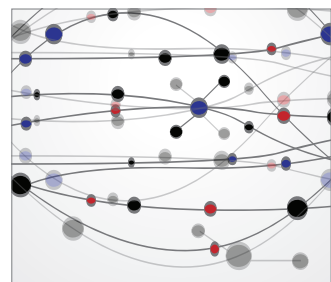

The Scientific World Journal
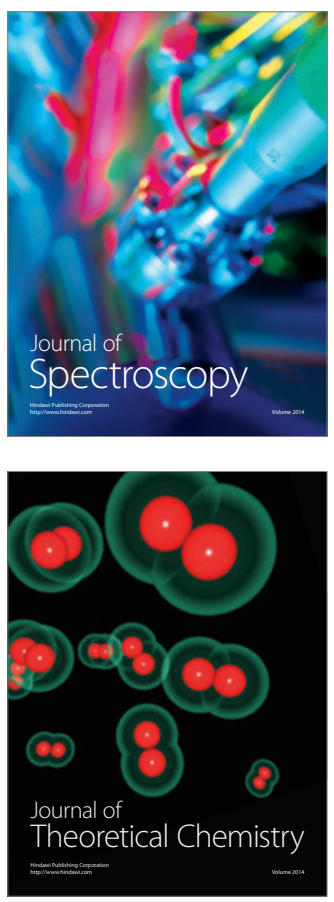
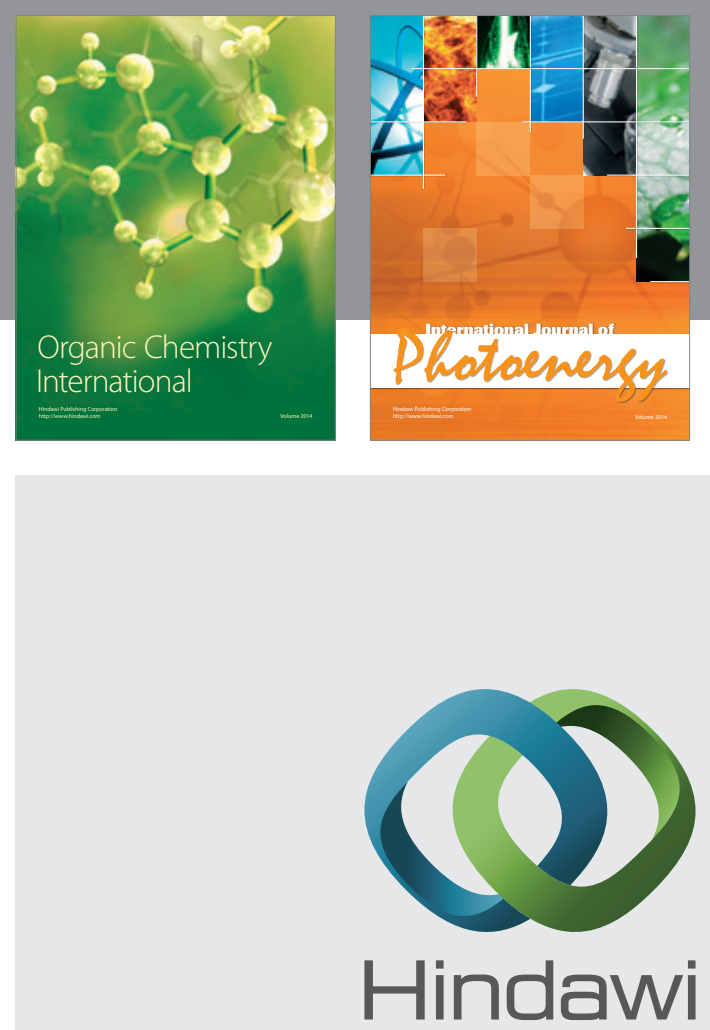

Submit your manuscripts at

http://www.hindawi.com
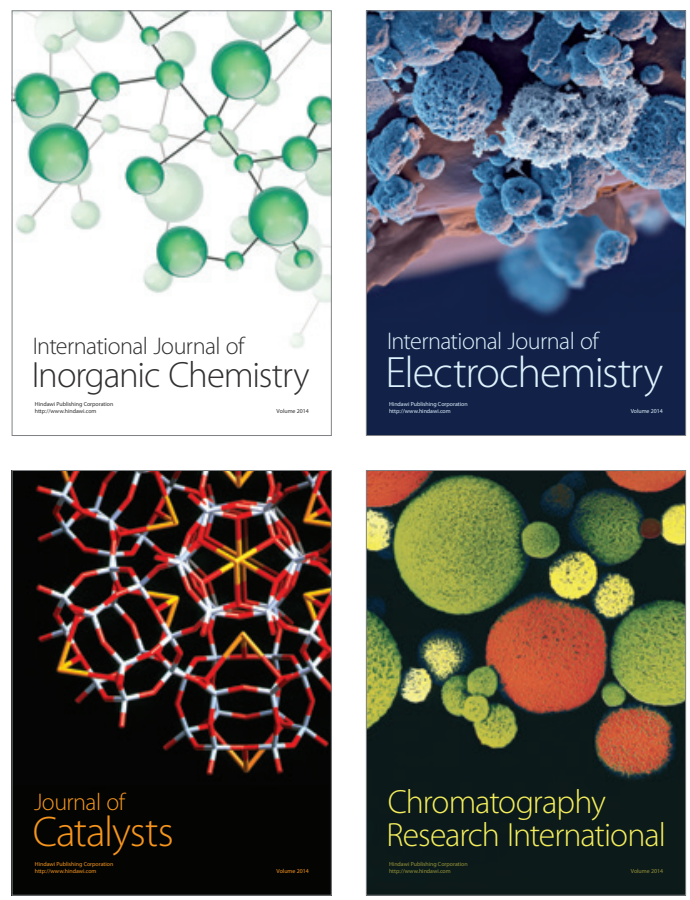
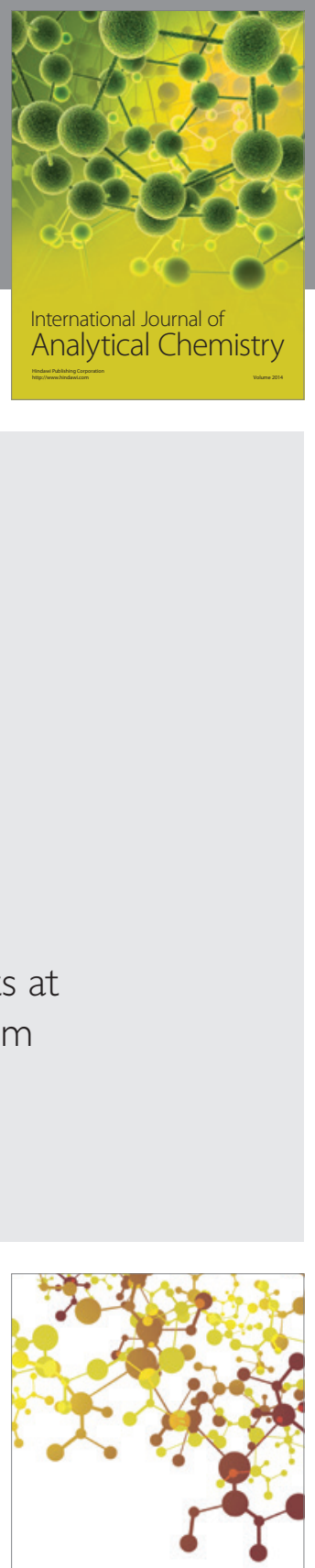

Journal of

Applied Chemistry
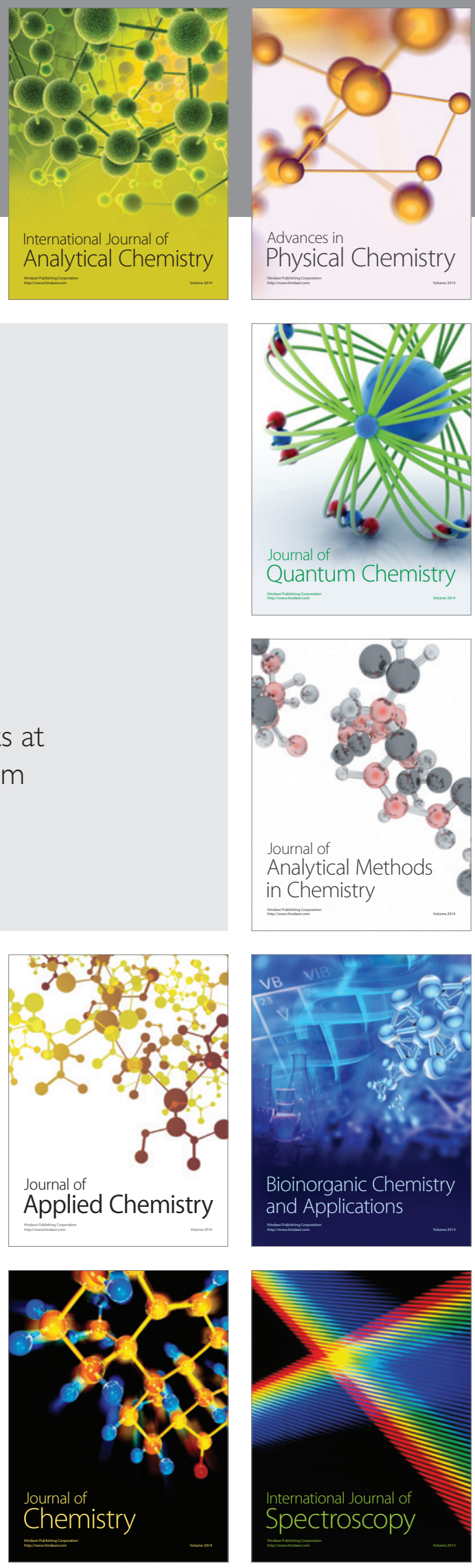